\title{
In vivo killing of Staphylococcus aureus using a light-activated antimicrobial agent Parjam S Zolfaghari ${ }^{1}$, Samantha Packer ${ }^{2}$, Mervyn Singer ${ }^{1}$, Sean P Nair ${ }^{2}$, Jon Bennett ${ }^{3}$, Cale Street ${ }^{4}$ and Michael Wilson*2
}

\begin{abstract}
Address: ${ }^{1}$ Bloomsbury Institute of Intensive Care Medicine, Wolfson Institute for Biomedical Research, University College London, Gower Street, London, WC1E 6BT, UK, ${ }^{2}$ Division of Microbial Disease, UCL Eastman Dental Institute, University College London, 256 Grays Inn Road, London, WC1X 8LD, UK, ${ }^{3}$ Peninsula College of Medicine and Dentistry, John Bull Building, Tamar Science Park, Plymouth, PL6 8BU, UK and ${ }^{4}$ Ondine Biopharma Corporation, 910-1100 Melville Street, Vancouver, BC, V6E 4A6, Canada
\end{abstract}

Email: Parjam S Zolfaghari - p.zolfaghari@ucl.ac.uk; Samantha Packer - s.lawton@eastman.ucl.ac.uk; Mervyn Singer - m.singer@ucl.ac.uk; Sean P Nair - s.nair@eastman.ucl.ac.uk; Jon Bennett - jon.bennett@pds.ac.uk; Cale Street - cstreet@ondinebiopharma.com; Michael Wilson* - m.wilson@eastman.ucl.ac.uk

* Corresponding author

Published: 4 February 2009

BMC Microbiology 2009, 9:27 doi:10.1 |86/|47|-2180-9-27
Received: 27 August 2008

Accepted: 4 February 2009

This article is available from: http://www.biomedcentral.com/I47I-2/80/9/27

(c) 2009 Zolfaghari et al; licensee BioMed Central Ltd.

This is an Open Access article distributed under the terms of the Creative Commons Attribution License (http://creativecommons.org/licenses/by/2.0), which permits unrestricted use, distribution, and reproduction in any medium, provided the original work is properly cited.

\begin{abstract}
Background: The widespread problem of antibiotic resistance in pathogens such as Staphylococcus aureus has prompted the search for new antimicrobial approaches. In this study we report for the first time the use of a light-activated antimicrobial agent, methylene blue, to kill an epidemic methicillin-resistant Staphylococcus aureus (EMRSA-16) strain in two mouse wound models.

Results: Following irradiation of wounds with $360 \mathrm{~J} / \mathrm{cm}^{2}$ of laser light $(670 \mathrm{~nm})$ in the presence of $100 \mu \mathrm{g} / \mathrm{ml}$ of methylene blue, a 25 -fold reduction in the number of viable EMRSA was seen. This was independent of the increase in temperature of the wounds associated with the treatment. Histological examination of the wounds revealed no difference between the photodynamic therapy (PDT)-treated wounds and the untreated wounds, all of which showed the same degree of inflammatory infiltration at 24 hours.

Conclusion: The results of this study demonstrate that PDT is effective at reducing the total number of viable EMRSA in a wound. This approach has promise as a means of treating wound infections caused by antibiotic-resistant microbes as well as for the elimination of such organisms from carriage sites.
\end{abstract}

\section{Background}

The emergence of resistant strains of bacteria such as methicillin-resistant Staphylococcus aureus (MRSA) poses a major challenge to healthcare. MRSA is a major cause of hospital-acquired infection throughout the world and is now also prevalent in the community as well as nursing and residential homes [1-3]. Of the Staph. aureus isolates in the United Kingdom in 2005, 43.6\% were found to be
MRSA and a point prevalence survey showed that $16 \%$ of intensive care patients were either colonized or infected with MRSA [4,5]. Mortality attributable to MRSA bacteraemia has been estimated to be $22 \%$ [6]. Increasing reports of resistance to antibiotics and antiseptics, have sparked a wave of research to find alternative antimicrobial strategies $[7,8]$. One such strategy involves the use of light-activated antimicrobial agents (LAAAs) in photodynamic 
therapy (PDT) [9]. Following excitation of the LAAA by light of an appropriate wavelength, singlet oxygen and free radicals are generated locally which directly attack the plasma membrane and other cellular targets resulting in bacteriolysis $[10,11]$. This could form the basis of an alternative approach for the eradication of such bacteria from superficial wounds, burns, varicose ulcers, pressure sores and carriage sites which are readily accessible to topical application of a LAAA and light.

In vitro experiments with PDT have demonstrated effective bactericidal activity of toluidine blue $\mathrm{O}(\mathrm{TBO})$ and methylene blue $(\mathrm{MB})$ as photosensitisers against MRSA [1214]. However, there are few in vivo studies which have looked at the effect of PDT in wounds, and in particular ones inoculated with drug-resistant bacteria. Furthermore there are no reports of the use of PDT in wounds colonised by MRSA. Two mouse studies that investigated the effect of PDT using a targeted polycationic photosensitiser demonstrated that PDT is effective at reducing the number of bacteria in excision wounds infected with Escherichia coli and Pseudomonas aeruginosa $[15,16]$. This was also shown in a burn wound model infected with bioluminescent Staphylococcus aureus treated with PDT using a cationic porphyrin [17]. However, within days of treatment, the bacterial luminescence reappeared, indicating incomplete bacterial killing.

A potential problem with PDT however, is its lack of specificity. Its cytotoxic effect, which destroys bacteria so effectively, leads to delayed burn-wound healing, presumably as a result of the reactive oxygen species acting on host tissue [17]. PDT also resulted in delayed healing of wounds in rat skin grafts [18]. However, treatment of wounds with laser light alone shows more diverse findings. Delayed wound healing was seen after delivery of high laser energy (211-420 J/cm²) in burn wounds [17] in contrast to unchanged or even improved speed of recovery when lower light energy (upto $75 \mathrm{~J} / \mathrm{cm}^{2}$ ) is used $[18,19]$.

A further factor associated with red light illumination is the generation of heat. This is partly due to absorption of light by endogenous chromophores as well as release of energy by the excited photosensitiser in the form of heat rather than the actual PDT effect. As far as we are aware, no in vivo study has investigated the local heating effect associated with PDT treatment for microbial eradication using methylene blue.

The aims of this study were to evaluate the effect of PDT, using methylene blue as a photosensitiser, on the survival of an epidemic strain of MRSA in excisional and superficial wounds in mice. The local heating effect associated with this PDT treatment was evaluated as well as the extent of collateral damage to host tissue.

\section{Results \\ Effect of PDT on the number of viable bacteria in the wounds}

Figures 1 and 2 show the number of EMRSA-16 isolated from the treated excision and superficial wounds and their respective control groups (wounds that did not receive any treatment, wounds that did not receive $\mathrm{MB}$, and those that were not irradiated).

Irradiation of the wounds in the presence of $\mathrm{MB}$ resulted in a significant reduction in the number of viable bacteria recovered from the wounds. This reduction was 25 fold (1.40 $\log _{10} \mathrm{CFU} /$ wound) in the excision wounds and 14 fold (1.15 $\log _{10} \mathrm{CFU} /$ wound) in the superficial scarified wounds.

\section{Effect of PDT on the temperature of the wounds}

To study the effects of irradiation on wound temperature, two groups of animals were examined. One group

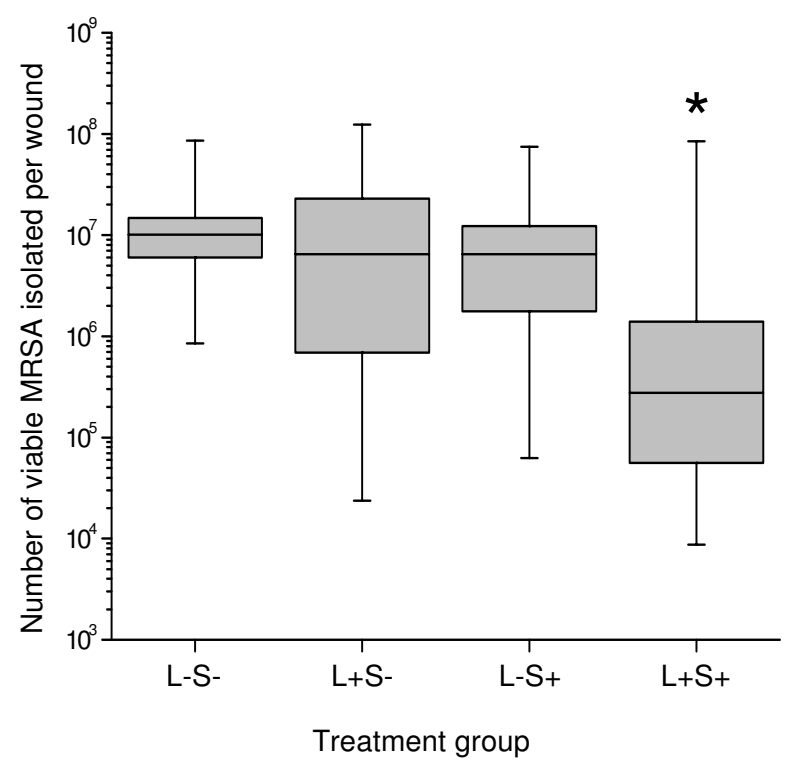

\section{Figure I}

Box- and whisker plot of the number of viable MRSA isolated from excision wounds treated with photodynamic therapy (PDT). The wounds were inoculated with EMRSA- 16 for one hour, treated with PDT using methylene blue and $665 \mathrm{~nm}$ laser light $\left(360 \mathrm{~J} / \mathrm{cm}^{2}\right)$ and examined immediately after treatment. A 25 fold reduction in the number of viable MRSA was seen in the PDT wounds $(L+S+)$ compared to the controls. Results are presented as box (median, $25^{\text {th }}$ and $75^{\text {th }}$ centiles) and whiskers (minimum and maximum values), $n=12$ per group $(*$ indicates $p<0.008)$. 


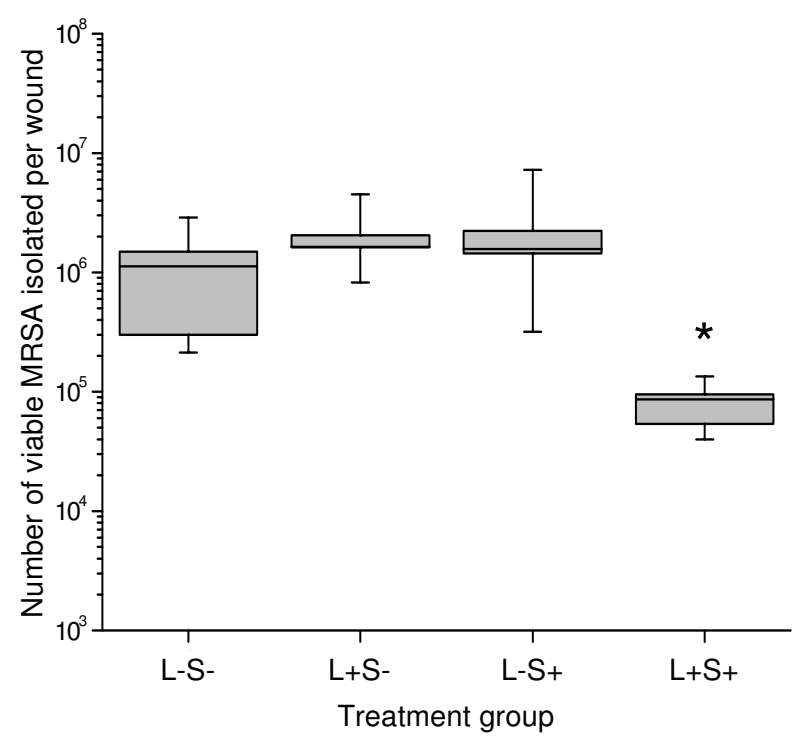

Figure 2

Box- and whisker plot of the number of viable MRSA isolated from superficial scarified wounds following photodynamic therapy. The wounds were examined immediately after treatment. A I4-fold reduction in the number of viable bacteria was observed in the PDT treated wounds $(\mathrm{L}+\mathrm{S}+)$ compared to the control wounds. (* indicates $p=0.002)$.

received only laser irradiation with no $\mathrm{MB}(\mathrm{L}+\mathrm{S}-; \mathrm{n}=3)$ while the other group had full PDT treatment with MB and laser irradiation $(\mathrm{L}+\mathrm{S}+; \mathrm{n}=3)$. The wound temperatures at the beginning of treatment were consistently lower than the core temperatures. The wound temperature in the animals treated with PDT rose by $13.4 \pm 0.5^{\circ} \mathrm{C}$ and the maximum temperature achieved in this group was $44.5^{\circ} \mathrm{C}$ (Figure 3 ). However, a smaller increase in temperature was noted in wounds irradiated with laser light in the absence of $\mathrm{MB}\left(7.1 \pm 2.6^{\circ} \mathrm{C}\right)$ with $40.1^{\circ} \mathrm{C}$ being the highest temperature reached in this group.

\section{Histological findings following PDT}

The cytotoxic effect of PDT on host tissue was examined in 18 biopsies from wounds treated with laser light and $\mathrm{MB}$ in combination. All exhibited a clear demarcation between wound and the skin and extended into adipose or loose areolar tissue on their deep aspect. Some included fragments of the underlying skeletal muscle. In the area of the wound, the epidermis had been removed to leave either a thin layer of the underlying connective tissue overlying the panniculus adiposus, or a wound base of adipose tissue. In contrast, the adjacent tissue had retained its epidermis complete with appendages. None of the wounds examined showed evidence of extensive tissue necrosis.
Normal wound architecture was seen in wounds that were sampled immediately after PDT (Figure 4A). By 24 hours there was a heavy lymphocytic infiltrate, which in some sections extended quite deeply to involve the underlying muscle. This was very prominent at the wound edges but less marked towards the centre (Figure 4B). When present in the latter areas, inflammatory cells could be seen infiltrating between dermal adipocytes. Wounds examined at 24 hours in the presence of bacteria exhibited a similar pattern of inflammatory cell infiltration regardless of whether they were treated with laser light and $M B$, either alone or in combination (Figure 4C). Moderate to heavy bacterial deposits were observed in some wounds and were generally localised to areas with a heavy fibrin slough. Observations were made on three biopsies for each experimental condition.

\section{Discussion}

There are many reports in the literature of the ability of light-activated antimicrobial agents to kill a wide range of microbes in the laboratory $[9,20]$. In some of these in vitro investigations, attempts have been made to model the in vivo situation by using biofilms of the target organisms [21] or by carrying out experiments in the presence of blood or serum. $[22,23]$ In this study we have taken this further by investigating the ability of a LAAA, methylene blue, to kill bacteria while present in a wound. Our in vivo model reflects the early stages of an infectious process i.e. the initial colonisation of a wound by a potential diseaseinducing organism. We used a strain of MRSA that is known to cause wound infections with significant clinical relevance, including fatal outcomes. The results of our study demonstrate for the first time that it is possible to reduce the number of viable MRSA present in a wound using the LAAA methylene blue when activated by $360 \mathrm{~J} /$ $\mathrm{cm}^{2}$ of light (with a wavelength of $665 \mathrm{~nm}$ - the absorbance maximum of methylene blue) from a low power laser.

Although substantial reductions in the viable count of MRSA in the wounds were achieved, the kills observed in this in vivo model were substantially lower than those reported in in vitro studies. Hence, using light doses as low as $43 \mathrm{~J} / \mathrm{cm}^{2}, 4.7 \log _{10}$ reductions in the viable count of a suspension of MRSA $\left(10^{10} \mathrm{CFU} / \mathrm{ml}\right)$ were obtained using the LAAA toluidine blue $\mathrm{O}$ (a phenothiazinium dye closely related to methylene blue) at a concentration of $12.5 \mu \mathrm{g} / \mathrm{ml} \mathrm{[12]}$. Wainwright et al. also reported that methylene blue and toluidine blue $\mathrm{O}$ are extremely effective LAAAs against MRSA in vitro [13]. To our knowledge, only three papers have been published on the use of LAAAs to kill S. aureus in vivo $[17,24,25]$. Each of these has used a different animal model and a different LAAA which makes comparisons with the present study difficult. However, in all of these studies the bacterial kills reported were 


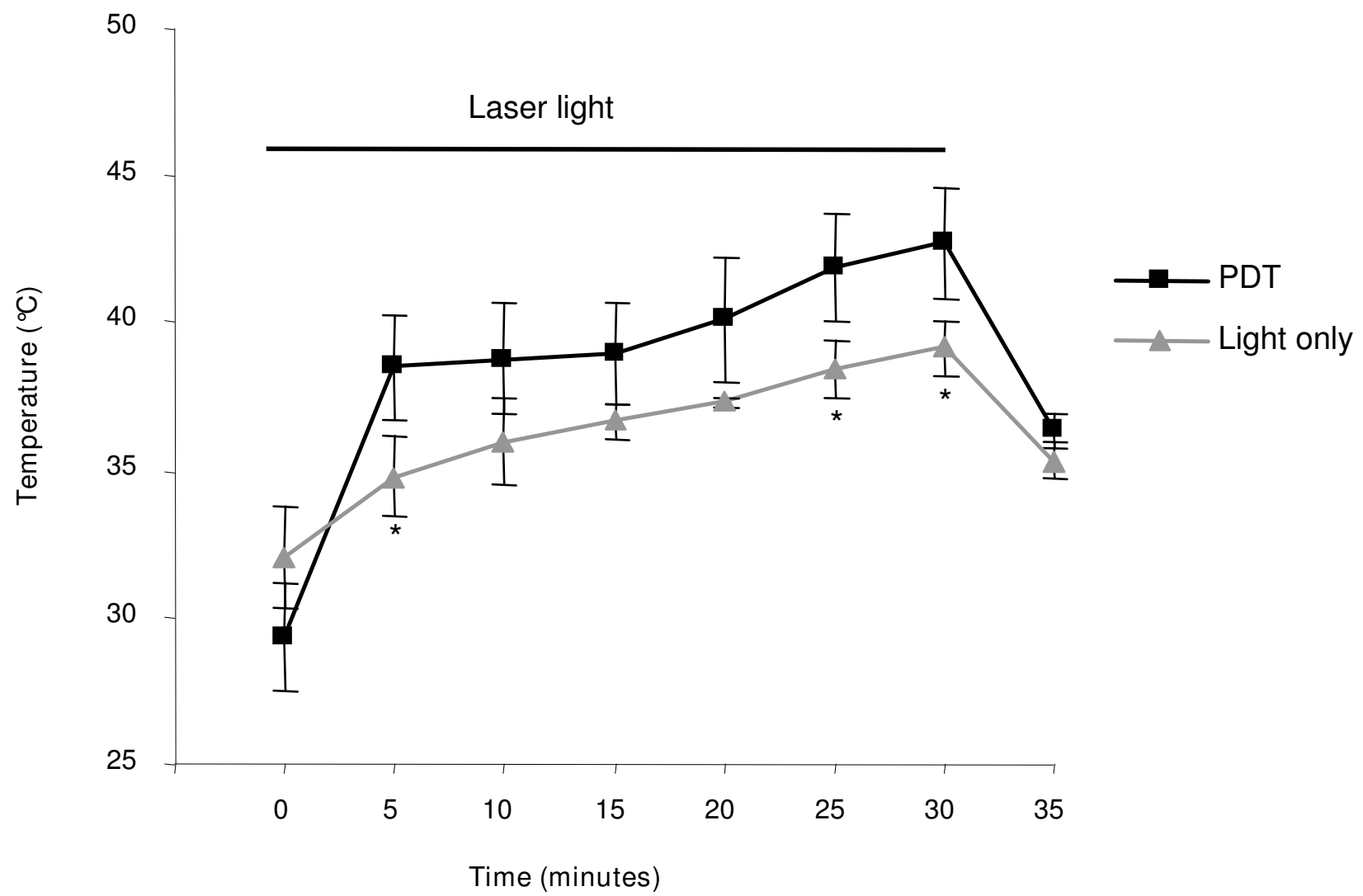

Figure 3

Effect of laser light alone and laser light with methylene blue on wound temperature. Temperature was measured using a thermistor tunnelled into the centre of the wounds. There was an immediate increase in the temperature of the wounds following the start of irradiation with laser light of $665 \mathrm{~nm}$ wavelength and power rating of $200 \mathrm{~mW} / \mathrm{cm}^{2}$. There was a bigger increase in temperature in the PDT treated wounds (black squares) than in the light only (grey triangles) treated group. The temperature dropped upon cessation of irradiation.

considerably lower than those that can be achieved in vitro. For example, when the LAAA meso-mono-phenyltri(N-methyl-4-pyridyl)-porphyrin (PTMPP) was used to kill $S$. aureus in burn wounds in mice, the kills achieved amounted to less than $2 \log _{10}$ units using a light dose of $211 \mathrm{~J} / \mathrm{cm}^{2}$ [17]. Much greater kills were attained in vitro using a considerably lower light dose $\left(0.6 \mathrm{~J} / \mathrm{cm}^{2}\right.$ compared with $\left.211 \mathrm{~J} / \mathrm{cm}^{2}\right)$ and concentration of PTMPP $(1.6 \mu \mathrm{M}$ in vitro compared with $500 \mu \mathrm{M}$ in vivo). Several factors may account for the reduced bactericidal effect observed in vivo including: (i) binding of the LAAA to host material thereby reducing the effective dose and resulting in the generation of singlet oxygen in regions remote from the target bacteria, (ii) absorption of laser light by LAAA bound to host tissues - this would result in shielding of any LAAA bound to bacteria preventing light activation and (iii) quenching of singlet oxygen by host molecules thereby protecting bacteria from its harmful effects. Some of these problems could be avoided, and hence greater kills achieved in vivo, by using a photosensitiser covalently linked to a bacterial targeting moiety $[15,24]$.

One aspect of the in vivo use of antimicrobial PDT that has not previously been investigated is the change in temperature of the host tissues accompanying the procedure. Treatment of basal cell carcinoma with 5-aminolevulinic acid and red light (590-700 nm) with a power density of $100 \mathrm{~mW} / \mathrm{cm}^{2}$ resulted in a $8-10^{\circ} \mathrm{C}$ change in the surface temperature of the lesion [26]. In our study we found that irradiation with $360 \mathrm{~J} / \mathrm{cm}^{2}$ of light in the presence of methylene blue resulted in a substantial rise in the wound temperature - the average maximum temperature at the centre of the wounds being $42.7 \pm 1.8^{\circ} \mathrm{C}$. However, it is very unlikely that such a temperature increase could 


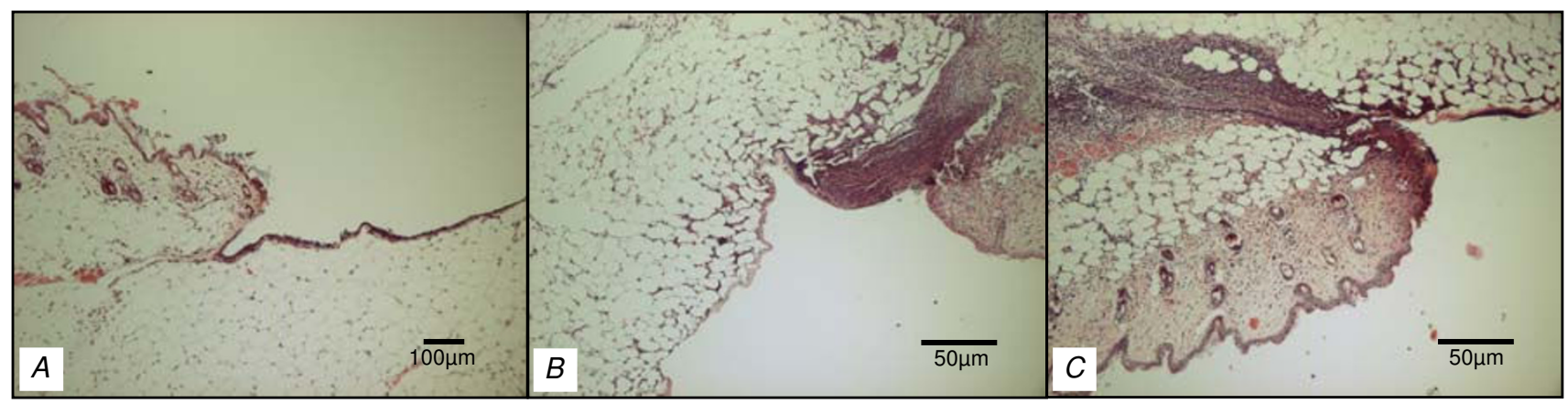

Figure 4

Haematoxylin \& Eosin stained sections of treated and control wounds. (A) Normal tissue architecture is seen in wounds taken immediately after treatment with photodynamic therapy. (B) At 24 hours, a dense cellular infiltrate appears at the wound edges inoculated with MRSA and treated with methylene blue only (L-S+). There are also smaller, focal lymphocytic aggregates infiltrating between subcutaneous adipocytes in the wound crater. (C) Following photodynamic therapy with laser light and methylene blue $(L+S+)$, the wounds show a dense cellular infiltrate at the edges and the subcutaneous fat very similar to the control wounds.

account for the bacterial kills observed $-S$. aureus is able to grow at temperatures as high as $45^{\circ} \mathrm{C}$ [27]. Furthermore, the decimal reduction time for the organism at a higher temperature of $50^{\circ} \mathrm{C}$ is of the order of 105 minutes whereas in the current study, the wound temperature was above $40^{\circ} \mathrm{C}$ for no longer than 10 minutes and did not reach $45^{\circ} \mathrm{C}$ [28].

Microscopic examination of biopsies immediately following treatment and after 24 hours did not reveal any tissue necrosis regardless of the experimental treatment applied. Thus, at the 24 hour time point the use of PDT did not amplify the effect of the wounding.

This study has demonstrated that substantial kills of MRSA can be achieved in an in vivo mouse wound model using the LAAA methylene blue, and without causing collateral damage to host tissues. These findings are significant for several reasons. They constitute the first report of the in vivo killing of MRSA using LAAAs. Secondly, they support the small, but growing, number of in vivo studies demonstrating that PDT is an effective antimicrobial. Thirdly, if such results can be reproduced in humans, the technique could be an effective means of preventing the colonisation of wounds by the organism and, possibly be used to eliminate MRSA from carriage sites such as the anterior nares. It should be noted that only a single application of PDT was used in this study and greater kills may be achieved through repeated application of the technique or by the "fractionation" of the light dose administered or in combination with other therapeutic agents such as antibiotics. We are currently investigating such modifications of the technique.
In this era of concern over the threat of the growing antibiotic resistance of pathogens such as MRSA to antibiotics, PDT offers an important advantage in that it is unlikely that the organism could develop resistance to this modality $[11,14]$. Another advantage of PDT is that, unlike the vast majority of antibiotics, it can also inactivate microbial virulence factors in addition to its microbicidal effect. Hence, the biological activities of the proteases of Pseudomonas aeruginosa and Porphyromonas gingivalis and the lipopolysaccharide of Escherichia coli have all been shown to be reduced by irradiation in the presence of a LAAA $[29,30]$. The future of LAAAs for the prevention and/or treatment of infectious diseases looks promising following the recent report of the use of methylene blue to successfully treat periodontitis - one of the most prevalent infectious diseases of humans.[31]

\section{Conclusion}

In this study we have shown that PDT using the light-activated antimicrobial agent, methylene blue, kills MRSA in superficial and deep excisional wounds in mice. However, killing is less effective than when performed in-vitro. This bactericidal effect was not due to the heat generated as a consequence of the treatment. Histological examination of the wounds showed neither collateral tissue necrosis nor architectural disturbance.

\section{Methods \\ Bacteria}

The organism used in this investigation was the prototypic UK epidemic MRSA: EMRSA-16 (NCTC 13143). EMRSA16 was maintained by weekly sub-culture on blood agar (BA, Oxoid Ltd, Basingstoke, UK) supplemented with 5\% 
(v/v) horse blood. For experimental purposes, a few colonies were inoculated into brain heart infusion broth (BA, Oxoid Ltd, Basingstoke, UK) and grown aerobically with shaking for 16 hours at $37^{\circ} \mathrm{C}$. Cells were then harvested by centrifugation, washed and resuspended in sterile phosphate buffered saline (PBS) to a concentration of $4 \times$ $10^{9}$ bacteria per ml. Twenty five $\mu \mathrm{l}$ of the bacterial suspension $\left(10^{8} \mathrm{CFU}\right.$ of EMRSA-16) was then added to the wound.

\section{Photosensitiser and laser}

Methylene blue (MB, Sigma, UK) solution was prepared fresh for each experiment in sterile PBS to a final concentration of $100 \mu \mathrm{g} / \mathrm{ml}$. The light source used was a $665 \mathrm{~nm}$ diode laser (PerioWave system, Ondine Biopharma, Vancouver, Canada) with a measured output of $200 \mathrm{~mW}$ distributed by a fibreoptic cable and a diffusing head. The source was held at a constant distance from the wound to produce a $1 \mathrm{~cm}^{2}$ circle of illumination.

\section{Animals}

All animal experiments were carried out in accordance with the Animals (Scientific Procedures) Act 1986 and with approval of the local Ethics Committee. Eight-week old female C57 Black mice (Charles River, Margate, Kent, UK), of 14-18 g body weight were housed in the local animal unit for 7 days prior to experimentation, with free access to food and water.

\section{Excisional wound model}

Mice were anaesthetised with an intramuscular injection of ketamine-xylazine mixture $(90 \mathrm{mg} / \mathrm{kg}$ ketamine, $9 \mathrm{mg} /$ $\mathrm{kg}$ xylazine), and their backs shaved and depilated with a commercial cream (Veet ${ }^{\circledast}$, Reckitt Benckiser, UK). Intramuscular Carpofen $(5 \mathrm{mg} / \mathrm{kg}$ ) was used to provide analgesia. At 45 minutes post-inoculation, the mice received a second dose of the anaesthetic mixture to allow for the subsequent treatment. The skin was washed with $70 \%(\mathrm{v} /$ v) ethanol and left to dry prior to wound creation. Excision wounds were created by pinching and lifting the skin of the back using sterile forceps and cutting a $6 \mathrm{~mm}$ circular $\left(28 \mathrm{~mm}^{2}\right)$ area using sharp scissors to cut down to the subcutaneous areolar tissue. Twenty-five $\mu \mathrm{l}$ of the bacterial suspension was then added to the wound $\left(10^{8} \mathrm{CFU}\right.$ of EMRSA-16), and incubated for one hour prior to treatment. MRSA was found to be the predominant bacterium colonising the wound at day 5 (data not included).

\section{Superficial wound model}

The preparation of the animals for this model was as described for the excisional wound model above. $25 \mathrm{~mm}^{2}$ square shaped wounds were created in the skin of the back by scarification using a $27 \mathrm{G}$ needle, run ten times parallel in one direction and another ten times perpendicular to the original tracks. The wounds were visibly red and mildly swollen after 30 minutes. Ten $\mu \mathrm{l}$ of the bacterial suspension was placed on the wound $\left(4 \times 10^{7} \mathrm{CFU}\right.$ of EMRSA-16), and incubated for one hour prior to treatment. This method also resulted in a reproducible MRSA wound colonisation model, which persisted for up to 5 days post inoculation (data not shown).

\section{Photodynamic therapy (PDT)}

All experiments were carried out under subdued room lighting. PDT was performed 1 hour after inoculating the wounds with the bacterial suspension. The excision wounds received $25 \mu \mathrm{l}$ of $\mathrm{MB}(100 \mu \mathrm{g} / \mathrm{ml})$ solely at the start of irradiation, whilst the superficial scarified wounds received $10 \mu \mathrm{l}$ of $\mathrm{MB}$ just before the start of irradiation and a further $10 \mu \mathrm{l}$ after 15 minutes of irradiation. The wounds were irradiated immediately after the application of $\mathrm{MB}$ and continued for 30 minutes. This equated to a total delivered light dose of $360 \mathrm{~J} / \mathrm{cm}^{2}$. Following the completion of treatment, a circular area of skin and associated subcutaneous tissue of $1 \mathrm{~cm}$ diameter with the wound at its centre, was removed using sterile scissors. These were then placed in $0.5 \mathrm{ml}$ Stuart's transport medium and shielded from light until delivery to the microbiology laboratory for processing and analysis within 2 hours. The animals were subsequently culled in accordance with the Animal Scientific Procedures act (1986).

Control groups were used to test the effect of $\mathrm{MB}$ alone (by incubating wounds in the dark for the equivalent time period as needed for irradiation, L-S+, where L denotes light treatment and $\mathrm{S}$ denotes photosensitiser), light alone (by illuminating wounds in the absence of $\mathrm{MB}, \mathrm{L}+\mathrm{S}-$ ). A final untreated control group received no $\mathrm{MB}$ or light illumination (L-S-). PBS was used instead of MB in the control wounds that received no MB.

Twelve mice per group were examined in the excision wound model, whereas 6 mice per group were used in the superficial scarified wound model.

In preliminary experiments, the dose of $\mathrm{MB}$ (concentration and volume of solution) was optimised to achieve maximum bacterial kill. For the excision wounds, $25 \mu \mathrm{l}$ of $\mathrm{MB}$ at a concentration of $100 \mu \mathrm{g} / \mathrm{ml}$ was most effective. However, for the superficial scarified wounds, the same concentration of $\mathrm{MB}$ was used but in a reduced volume of $10 \mu \mathrm{l}$ administered at two separate time-points, $15 \mathrm{~min}$ utes apart. The delivered light dose which produced the greatest bacterial kill in both types of wounds was optimised to $360 \mathrm{~J} / \mathrm{cm}^{2}$, although light doses of $180 \mathrm{~J} / \mathrm{cm}^{2}$ also reduced the number of viable bacteria recovered.

\section{Processing of tissue samples}

Using a micro-Eppendorf pestle, the tissue in Stuart's transport medium was minced to release the bacteria 
within the wound. Tissue samples treated with $\mathrm{MB}$ were kept in the dark during processing. The contents of the Eppendorf tube were transferred into $4.5 \mathrm{ml}$ of PBS. Aliquots of serial 10-fold dilutions of the suspension were plated onto half plates of BA and mannitol salt agar (MSA). Plates were incubated at $37^{\circ} \mathrm{C}$ in air for 36 hours before colonies of EMRSA-16 were counted. Results represent the mean CFU of EMRSA-16 recovered per wound based on counts from both BA and MSA plates for each sample.

\section{Histological evaluation}

For these studies, wounds were removed either immediately or after 24 hours following treatment and fixed in $4 \%$ formal saline for 24 hours. The specimens were processed and embedded in paraffin wax. $6 \mu \mathrm{m}$ histological sections were cut stained with haematoxylin-eosin and examined by light microscopy.

\section{Wound temperature studies}

Following creation and inoculation of the excision wounds with bacteria for 1 hour, a $1 \mathrm{~mm}$ diameter thermistor (Thermilinear ${ }^{\circledast}$ component, Yellow Spring Instruments Co., Ohio, USA) was tunnelled subcutaneously from an entry point $2 \mathrm{~cm}$ away from the wound to its centre, avoiding disruption of the wound integrity. PDT was then performed as above and temperature changes plotted. A single control group had wounds irradiated with laser light in the absence of MB (L+S-).

\section{Statistical analysis}

Data are expressed as mean \pm standard error or median (95\% confidence intervals). Group comparison for continuous variables was tested with the t-test (for temperature changes) and Mann Whitney U test for the rest of the data. Multiple comparisons increase the risk of type I errors. In order to prevent such errors, we used the Bonferroni method and divided the 5\% alpha level by the number of comparisons. Hence, when pair-wise comparisons were performed between treatment groups, p was only significant if it was $<0.008$. All tests were performed with the use of SPSS 14.0 for Windows.

\section{Abbreviations}

EMRSA: Epidemic methicillin-resistant Staph. aureus; LAAA: Light-activated antimicrobial agent; $\mathbf{L}+\mathrm{S}+$ : Wounds treated with both methylene blue and laser light; $\mathrm{L}+\mathrm{S}$-: Control wounds treated with laser light only; L-S+: Control wounds treated with methylene blue only; L-S-: Control wounds with no treatment; MB: Methylene blue; MRSA: Methicillin-resistant Staph. Aureus; PDT: Photodynamic therapy; TBO: Toluidine blue O; CFU: Colony forming units.

\section{Competing interests}

MW is a member of the Scientific Advisory Board of Ondine Biopharma Inc. and holds shares in this company, PSZ received financial income from Ondine Biopharma Inc. during the course of the study. CS is director of research at Ondine Biopharma Inc. Other authors: None to declare.

\section{Authors' contributions}

PSZ carried out all the animal experiments including all photodynamic therapy, drafted the manuscript and performed the statistical analysis. SP carried out all microbiological work and analysis and helped draft the manuscript. MS participated in the design of the study and helped drafting the manuscript. JB carried out histological examination of the wounds and helped to draft the manuscript. SPN and MW conceived the study, and participated in its design and coordination and helped to draft the manuscript. CS participated in the design of the study. All authors read and approved the final manuscript.

\section{Acknowledgements}

This work was supported by Ondine Biopharma Corporation (Canada).

We would like to thank Mr. Paul Darkins for help with the preparation of sections for histopathology and Dr Alain Rudiger for help with the statistical analysis.

\section{References}

I. Ayliffe GAJ, Casewell MSC, Cookson BD, et al.: Revised guidelines for the control of methicillin-resistant Staphylococcus aureus infection in hospitals. British Society for Antimicrobial Chemotherapy, Hospital Infection Society and the Infection Control Nurses Association. J Hosp Infect 1998, 39:253-90.

2. Gould IM: Community-acquired MRSA: can we control it? Lancet 2006, 368(9538):824-6.

3. Ayliffe GAJ, Brumfitt W, Casewell MWC, Cookson BD, et al.: Report of a combined working party of the Hospital Infect Soc \& Brit Soc Antimicrob Chemother. J Hosp Infect 1995, 3 I: I-I 2.

4. EARSS: European Antimicrobial Resistance Surveillance System. 2005 [http://www.eurosurveillance.org].

5. Hails J, Kwaku F, Wilson AP, Bellingan G, Singer M: Large variation in MRSA policies, procedures and prevalence in English intensive care units: a questionnaire analysis. Intensive Care Med 2003, 29:48I-3.

6. Cosgrove SE, Qi Y, Kaye KS, Harbarth S, Karchmer AW, Carmeli Y: The impact of methicillin resistance in Staphylococcus aureus bacteremia on patient outcomes: mortality, length of stay, and hospital charges. Infect Control Hosp Epidemiol 2005, 26:166-74.

7. Deurenberg RH, Vink C, Kalenic S, Friedrich AW, Bruggeman CA, Stobberingh EE: The molecular evolution of methicillin-resistant Staphylococcus aureus. Clin Microbiol Infect 2007, 13:222-35.

8. Noguchi N, Suwa J, Narui K, Sasatsu M, Ito T, Hiramatsu K, Song JL: Susceptibilities to antiseptic agents and distribution of antiseptic-resistance genes qacA/B and smr of methicillin-resistant Staphylococcus aureus isolated in Asia during 1998 and 1999. J Med Microbiol 2005, 54:557-65.

9. Hamblin MR, Hasan T: Photodynamic therapy: a new antimicrobial approach to infectious disease? Photochem Photobiol Sci 2004, 3:436-50.

10. Jori G, Fabris C, Soncin M, Ferro S, Coppellotti O, Dei D, Fantetti L, Chiti G, Roncucci G: Photodynamic therapy in the treatment of microbial infections: basic principles and perspective applications. Lasers Surg Med 2006, 38:468-8I.

II. Wainwright $M$ : Photodynamic antimicrobial chemotherapy (PACT). J Antimicrob Chemother 1998, 42:13-28. 
12. Wilson M, Yianni C: Killing of methicillin-resistant Staphylococcus aureus by low-power laser light. J Med Microbiol 1995, 42:62-6.

13. Wainwright M, Phoenix DA, Laycock SL, Wareing DR, Wright PA: Photobactericidal activity of phenothiazinium dyes against methicillin-resistant strains of Staphylococcus aureus. FEMS Microbiol Lett 1998, 160:177-8I.

14. Zeina B, Greenman J, Purcell WM, Das B: Killing of cutaneous microbial species by photodynamic therapy. $\mathrm{Br} J$ Dermatol 200I, 144:274-8.

15. Hamblin MR, O'Donnell DA, Murthy N, Contag CH, Hasan T: Rapid control of wound infections by targeted photodynamic therapy monitored by in vivo bioluminescence imaging. Photochem Photobiol 2002, 75:5I-7.

16. Hamblin MR, Zahra T, Contag CH, McManus AT, Hasan T: Optical monitoring and treatment of potentially lethal wound infections in vivo. J Infect Dis 2003, 187:1717-25.

17. Lambrechts SA, Demidova TN, Aalders MC, Hasan T, Hamblin MR Photodynamic therapy for Staphylococcus aureus infected burn wounds in mice. Photochem Photobiol Sci 2005, 4:503-9.

18. Kübler A, Finley RK 3rd, Born IA, Mang TS: Effect of photodynamic therapy on the healing of a rat skin flap and its implication for head and neck reconstructive surgery. Lasers Surg Med 1996, 18:397-405.

19. Lucas C, Criens-Poublon LJ, Cockrell CT, de Haan RJ: Wound healing in cell studies and animal model experiments by Low Level Laser Therapy; were clinical studies justified? a systematic review. Lasers Med Sci 2002, 17: I 10-34.

20. Jori G, Brown SB: Photosensitized inactivation of microorganisms. Photochem Photobiol Sci 2004, 3:403-5.

21. Sharma M, Visai L, Bragheri F, Cristiani I, Gupta PK, Pietro Speziale P: Toluidine Blue-Mediated Photodynamic Effects on Staphylococcal Bio?Ims. Antimicrob Agents Chemother 2008, 52:299-305.

22. O'Neill JF, Hope CK, Wilson M: Oral bacteria in multi-species biofilms can be killed by red light in the presence of toluidine blue. Lasers Surg 2002, 31 :86-90.

23. Wilson M, Pratten J: Lethal photosensitisation of Staphylococcus aureus in vitro: effect of growth phase, serum, and preirradiation time. Lasers Surg Med 1995, 16:272-6.

24. Gad F, Zahra T, Francis KP, Hasan T, Hamblin MR: Targeted photodynamic therapy of established soft-tissue infections in mice. Photochem Photobiol Sci 2004, 3:45I-8.

25. Orenstein A, Klein D, Kopolovic J, Winkler E, Malik Z, Keller N, Nitzan $Y$ : The use of porphyrins for eradication of Staphylococcus aureus in burn wound infections. FEMS Immunol Med Microbio 1997, 19:307-14.

26. Orenstein A, Kostenich G, Tsur H, Kogan L, Malik Z: Temperature monitoring during photodynamic therapy of skin tumors with topical 5-aminolevulinic acid application. Cancer Lett 1995, 93:227-32.

27. Benjamin E, Reznik A, Benjamin E, Williams AL: Mathematical models for conventional and microwave thermal deactivation of Enterococcus faecalis, Staphylococcus aureus and Escherichia coli. Cell Mol Biol (Noisy-le-grand) 2007, 53:42-8.

28. Kennedy J, Blair IS, McDowell DA, Bolton DJ: An investigation of the thermal inactivation of Staphylococcus aureus and the potential for increased thermotolerance as a result of chilled storage. J Appl Microbiol 2005, 99: I229-35.

29. Packer S, Bhatti M, Burns T, Wilson M: Inactivation of Proteolytic Enzymes from Porphyromonas gingivalis Using Light-activated Agents. Lasers Med Sci 2000, I5:24-30.

30. Komerik N, Wilson M, Poole S: The effect of photodynamic action on two virulence factors of gram-negative bacteria. Photochem Photobiol 2000, 72:676-80.

31. Andersen R, Loebel N, Hammond D, Wilson M: Treatment of periodontal disease by photodisinfection compared to scaling and root planing. J Clin Dent 2007, 18:34-8.

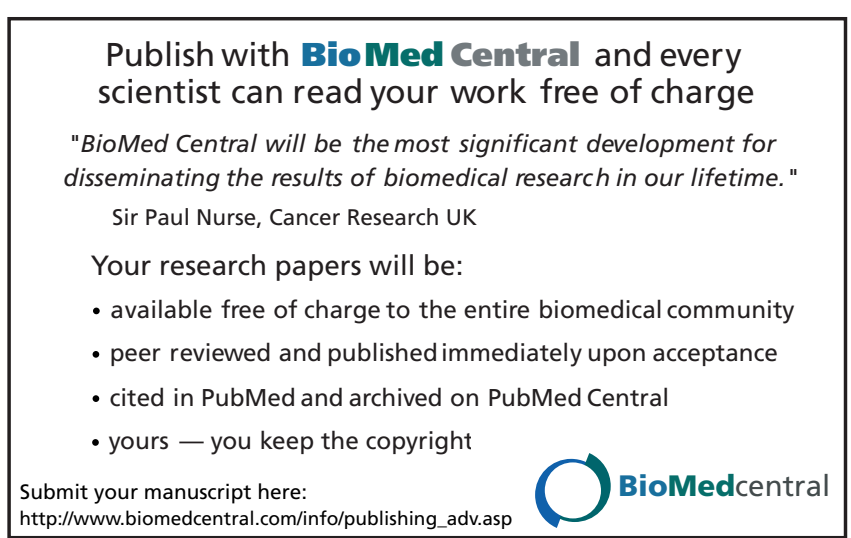

